\title{
Occurrence and assessment of veterinary antibiotics in swine manures: A case study in East China
}

\author{
CHEN YongShan ${ }^{1,2}$, ZHANG HaiBo $^{1}$, LUO YongMing ${ }^{1,2,3^{*}} \&$ SONG Jing ${ }^{1}$ \\ ${ }^{1}$ Key Laboratory of Soil Environment and Pollution Remediation, Institute of Soil Science, Chinese Academy of Sciences, Nanjing 210008, China; \\ ${ }^{2}$ Graduate School of the Chinese Academy of Sciences, Beijing 100049, China; \\ ${ }^{3}$ Yantai Institute of Coastal Zone Research, Chinese Academy of Sciences, Yantai 264003, China
}

Received February 15, 2011; accepted August 18, 2011

\begin{abstract}
We investigated the occurrence of 14 selected antibiotics including five therapeutic classes of tetracyclines, sulfonamides, macrolides, fluoroquinolones and chloramphenicols in manures collected from four swine farms of different sizes in eastern China. Tetracyclines (tetracycline, oxytetracycline, chlortetracycline, and doxycycline) and sulfadiazine were the most prominent contaminants in the manure samples, with maximum concentrations reaching $98.2 \times 10^{3}, 354.0 \times 10^{3}, 139.4 \times 10^{3}, 37.2 \times 10^{3}$, and $7.1 \times$ $10^{3} \mu \mathrm{g} / \mathrm{kg}$, respectively. The occurrence of these compounds was dependent on breeding scale, animal type, and breeding season. Manure storage and vermiculture were not able to effectively deplete the heavier contaminants (tetracyclines and sulfadiazine), resulting in high levels of these chemicals remaining in manures. Therefore, the occurrence of these antibiotics in agricultural soils $(0.1-205.1 \mu \mathrm{g} / \mathrm{kg}$ ) collected from four types of agricultural land (pear orchard, tea plantation, bamboo forest, and paddy field) near the studied farms, was a reflection of manure application. However, the extremely high concentrations of antibiotics in manures were unlikely from feed consumption, but from other direct forms of medicine application.
\end{abstract}

veterinary antibiotics, pigs, swine farm, manure, feed, manure management

Citation: Chen Y S, Zhang H B, Luo Y M, et al. Occurrence and assessment of veterinary antibiotics in swine manures: A case study in East China. Chin Sci Bull, 2012, 57: 606-614, doi: 10.1007/s11434-011-4830-3

Veterinary antibiotics are widely used to treat disease and protect the health of animals. Farmers often use these drugs in animal husbandry to improve and maintain the viability of their operations. Antibiotics play a major role in livestock production and their use has been increasing globally $[1,2]$. However, they are poorly absorbed by animals, resulting in as much as $30 \%-90 \%$ of the parent compound or its metabolites being excreted in feces and urine [2,3]. Significant concentrations of veterinary antibiotics have been detected in wastes from livestock farms, and also in environmental matrices such as surface waters, groundwaters, and soils [4-8]. Many questions have arisen about the potential negative impacts of veterinary medicines on organisms in the environment and on human health $[1,9,10]$.

Drugs are delivered to animals through feed or water, or

*Corresponding author (email: ymluo@yic.ac.cn) by injection, implant, drench, paste, orally, topically, pour on, and bolus. Most livestock operations in the United States (about 91\%) use antibiotics in feed to prevent disease and promote growth during the production process [2]. Antibiotic dose in feeds varies from 3.0 to $220.0 \mathrm{~g} / \mathrm{kg}$, depending on sizes and types of animals, and medicines [8]. However, the prescription patterns (delivery route and dose) seem to be more complex in China, perhaps owing to a lack of management systems for medicine application and the backwardness of operations. Considerable variation among different farms, breeding seasons, and breeding scales, therefore occurs in the use of veterinary antibiotics.

In China, more than 8000 t of antibiotics are currently used in intensively managed animal husbandry each year [11]. This means 2400-7200 t of antibiotics will be discharged into the environment every year by livestock industries, assuming excretion rates of $30 \%-90 \%$. In fact, very 
high concentrations of veterinary antibiotics (up to hundreds of $\mathrm{mg} / \mathrm{kg}$ or $\mu \mathrm{g} / \mathrm{L}$ ) have frequently been found in animal excreta in China $[8,12,13]$. Therefore, surface waters, agricultural soils, and groundwaters, which have directly or indirectly received treated or untreated wastes, may display high levels of antibiotic contamination $[7,14,15]$. Unfortunately, there has been no attempt to control the widespread distribution of these compounds in the environment. Current projects, based on wastewater treatment plants and manure storage/compost facilities, are primarily designed for control of conventional pollutants such as nitrogen, phosphorus, chemical oxygen demand (COD) and pathogens $[11,16]$. Veterinary antibiotics and their degradation products may potentially degrade further during operating processes, depending on the physicochemical properties and structure of the antibiotic [11,17]. In contrast, some compounds may persist for days to months, including metabolites reverting to parent compounds [18].

Pig breeding is a main part of animal husbandry in China, with a total number of $107308 \times 10^{4}$ head raised in 2008 [19]. This indicates that large quantities of veterinary antibiotics will be used, resulting in severe environmental pollution. However, most concerns are directed at nutrient problems derived from animal husbandry because of eutrophication in Chinese surface waters [20,21]. Our main objectives were therefore (i) to investigate the occurrence and variation of selected antibiotics in manures from different pig feeding operations, (ii) to study the residues of selected antibiotics in manure during manure management, and (iii) to make a preliminary assessment of the contributions of feed additives to the contamination levels of selected antibiotics in manures and soils.

\section{Materials and methods}

\subsection{Chemicals and standards}

Fourteen selected antibiotic compounds were purchased from Sigma-Aldrich Corp., St. Louis, Missouri, USA (Table 1). ${ }^{13} \mathrm{C}_{3}$-caffeine solution $(100 \mu \mathrm{g} / \mathrm{mL}$ in methanol) was obtained from Cambridge Isotope Laboratories Inc.(Andover, Massachusetts, USA). HPLC grade methanol, analytical grade formic acid (99\%), citric acid-monohydrate, sodium phosphate-dibasic anhydrous, and disodium ethylene diaminetetraacetic acid $\left(\mathrm{Na}_{2} \mathrm{EDTA}\right)$ were purchased from $\mathrm{Si}$ nopharm Chemical Reagent Co. Ltd. (Shanghai, China). All the antibiotics were dissolved in methanol and stored in a freezer; working solutions were prepared immediately before the experimentation by dilution of stock solutions. Erythromycin- $\mathrm{H}_{2} \mathrm{O}$, the major degradation product of erythromycin, was obtained by acidification of erythromycin using the method described by Mcardell et al. [22]. Ultra-pure water was prepared with a Milli-Q water purification system (Millipore, Bedford, Massachusetts). Oasis HLB cartridges, $6 \mathrm{~mL} / 500 \mathrm{mg}$, used for solid-phase extraction (SPE), were purchased from Water Oasis Co. (Milford, Massachusetts) and SAX cartridges (3 mL/500 mg) combined with HLB cartridges and used in wastewater preparation were sourced from Supelco Co. (Bellefonte, Pennsylvania, USA).

\subsection{Sample location and collection}

The pig farms selected for study were located in a suburb of Hangzhou City, Zhejiang Province, East China, where severe pollution has occurred due to rapid economic development

Table 1 Optimized MS/MS parameters for the target antibiotics

\begin{tabular}{|c|c|c|c|c|c|c|}
\hline Compound & Abbreviation & Molecular weight & Parent $(\mathrm{m} / \mathrm{z})$ & Daughter $(\mathrm{m} / \mathrm{z})^{\mathrm{a})}$ & Cone $(\mathrm{V})$ & Collision (V) \\
\hline Tetracycline & $\mathrm{TC}$ & 444.5 & 445.3 & $\mathbf{1 5 4}, 410,427$ & $30,20,10$ & $35,35,30$ \\
\hline Oxytetracycline & OTC & 460.4 & 461.3 & $\mathbf{3 8 1}, 426,443$ & $30,20,15$ & $40,40,40$ \\
\hline Chlortetracycline & CTC & 478.9 & 479.1 & $\mathbf{1 5 4}, 444,462$ & $30,20,15$ & $35,35,35$ \\
\hline Doxycycline & $\mathrm{DXC}$ & 444.5 & 445.1 & $\mathbf{1 5 4}, 410,428$ & $30,20,15$ & $35,35,35$ \\
\hline Sulfadiazine & SD & 250.3 & 251.1 & $91.9, \mathbf{1 5 5 . 9}$ & 30,15 & 30,30 \\
\hline Sulfamethoxazole & SMX & 253.3 & 254.2 & $92.2, \mathbf{1 0 7 . 9}$ & 30,20 & 30,30 \\
\hline Sulfamethazine & SMT & 278.3 & 279.1 & $91.9, \mathbf{1 5 5 . 9}, 186$ & $30,20,20$ & $35,35,35$ \\
\hline Norfloxacin & NFC & 319.3 & 320.1 & $276.4, \mathbf{3 0 2 . 2}$ & 20,20 & 40,40 \\
\hline Ofloxacin & OFC & 361.4 & 362.3 & $302, \mathbf{2 6 1}$ & 20,20 & 40,40 \\
\hline Enythromycin- $\mathrm{H}_{2} \mathrm{O}$ & ETM- $\mathrm{H}_{2} \mathrm{O}$ & 734.0 & 734.5 & $\mathbf{1 5 8}, 576.3$ & 35,20 & 35,35 \\
\hline Roxithromycin & RTM & 837.1 & 837.6 & $\mathbf{1 5 8}, 679.4$ & 39,20 & 35,35 \\
\hline Thiamphenical & TPC & 356.2 & 354.1 & $\mathbf{1 8 5}, 290$ & 20,10 & 35,35 \\
\hline Florfenicol & FFC & 358.2 & 356.1 & $\mathbf{1 8 5}, 336$ & 20,10 & 30,30 \\
\hline
\end{tabular}

a) Daughter ions in bold were used for quantitative purposes, other daughter ions were used for confirmative purposes. 
and urbanization. Swine manures were collected from four swine farms, designated farm A (breeding scale about 5000 head per year), farm B (about 20000 head per year), farm C (about 700 head per year), and farm D (individual household breeding, about 30-50 head per year). All four farms were surveyed in spring (March 2009) except for farm B which was also surveyed in summer and winter (July and December 2009). Manure samples from the farms were collected from finishing pigs except for farms $\mathrm{B}$ and $\mathrm{D}$, in which sows or young pigs were also studied in spring. Manure samples were collected at a depth of $10 \mathrm{~cm}$ below the surface layer in manure heaps. Ten discrete subsamples were collected, and composite samples were prepared by mixing equal quantities of subsamples. About $500 \mathrm{~g}$ of each final sample, selected by the quadripartite method, was taken to the laboratory and stored at $-20^{\circ} \mathrm{C}$ prior to analysis. To evaluate the contamination sources of the antibiotics present, four types of swine feed were also collected from farm A and B. Feed samples were quartered from the feedbags, placed in $\mathrm{PVC}$ bottles and stored at $-20^{\circ} \mathrm{C}$ until analysis. The wastes from two manure disposal processes (manure storage and vermiculture) were also collected to investigate antibiotic residues. These solid samples were collected in a similar fashion to the manure samples. In addition, four surface soil samples were collected from agricultural fields (pear orchard, tea plantation, bamboo forest and paddy field) near the farms $(<5 \mathrm{~km})$. At each field, ten subsamples (at a depth of 0-20 cm over $1000 \mathrm{~m}^{2}$ ) were collected and bulked together to form one composite sample. The final $1 \mathrm{~kg}$ of soil from each field was selected by the quadripartite method and taken to the laboratory.

\subsection{Sample preparation}

All samples were subjected to ultrasonic extraction coupled with SPE following procedures previously described for solid samples (soil or manure) [12,23]. Samples were freeze-dried using a FreeZone 2.5 L Freeze Dry System (Labconco Corp., Kansas City, MO), and then ground to pass through a $0.85 \mathrm{~mm}$ sieve $(0.3 \mathrm{~mm}$ for soils $)$ and homogenized before extraction. The samples (1.000 $\mathrm{g}$ of manure; $2.000 \mathrm{~g}$ of feeds and soils) were ultrasonically extracted in glass centrifuge tubes with $20 \mathrm{~mL}$ of $1 / 1(\mathrm{v} / \mathrm{v})$ methanol/EDTA-McIlvaine buffer ( $\mathrm{pH} \mathrm{4.0)}$ ) for $30 \mathrm{~min}$. Extracts were then separated by centrifugation and the process was repeated three times. Supernatants were combined and evaporated to half the original volume (total $60 \mathrm{~mL}$ ) using $\mathrm{K}-\mathrm{D}$ apparatus to remove the methanol. The residual liquid was then diluted to $100 \mathrm{~mL}$.

Diluents were cleaned up and extracted using SAX-HLB SPE cartridges set up in tandem and pre-conditioned sequentially with $10 \mathrm{~mL}$ of methanol and $10 \mathrm{~mL}$ of ultra-pure water, at a flow rate of approximately $5.0 \mathrm{~mL} / \mathrm{min}$. Samples were then passed through SPE columns at a flow rate of approximately $3.0 \mathrm{~mL} / \mathrm{min}$. After the water had passed through the combined cartridges, the SAX columns were removed and the HLB cartridges were rinsed with $10 \mathrm{~mL}$ of ultra-pure water and dried under nitrogen gas for $30 \mathrm{~min}$ at a flow rate of $2-4 \mathrm{~mL} / \mathrm{min}$. After drying, each cartridge was eluted with $2 \mathrm{~mL}$ methanol (containing $0.1 \%$ formic acid $(\mathrm{v} / \mathrm{v}))$ with a retention time of 2-3 min and then with $8 \mathrm{~mL}$ methanol at a rate of $<3.0 \mathrm{~mL} / \mathrm{min}$. Analytes were collected in a $15 \mathrm{~mL}$ brown glass vial and the volume was reduced to under $1.0 \mathrm{~mL}$ by purging with nitrogen. A $10 \mu \mathrm{L}$ volume of internal standard $\left({ }^{13} \mathrm{C}_{3}\right.$-caffeine, $\left.1.0 \mathrm{mg} / \mathrm{L}\right)$ was added and mixed with the residual liquid, and the final volume in each vial was adjusted to exactly $1.0 \mathrm{~mL}$ with methanol for ultra performance liquid chromatography (UPLC) analysis.

\subsection{UPLC and MS-MS system}

To separate antibiotic residues, we use ultra-performance liquid chromatography- and electrospray ionization tandem mass spectrometry with a TQ Detector (Acquity, Waters Corp., Milford, Massachusetts, USA). Samples were separated on a Waters Acquity UPLC BEH C18 column $(1.7 \mu \mathrm{m}$, $2.0 \mathrm{~mm} \times 100 \mathrm{~mm}$ ) maintained at $30^{\circ} \mathrm{C}$. The mobile phase A consisted of $99.9 \%$ water and $0.1 \%$ formic acid, and mobile phase B consisted of $99.9 \%$ methanol mixed with $0.1 \%$ formic acid. The gradient elution was set as follows: beginning at $90 \% \mathrm{~A}, 0-2 \mathrm{~min}$ linear gradient to $80 \% \mathrm{~A}, 2-7 \mathrm{~min}$ $20 \%$ A, 7-10 min linear gradient to $10 \% \mathrm{~A}$, then the eluent was brought to $100 \% \mathrm{~B}$ and maintained for $10 \mathrm{~min}$. The injection volume was $5 \mu \mathrm{L}$ and the flow rate was $0.3 \mathrm{~mL} / \mathrm{min}$. Ionization was performed in the positive mode for tetracyclines, sulfonamides, macrolides, and fluoroquinolones and in the negative mode for chloramphenicols. MS/MS was operated at unit resolution in the multiple reactions monitoring (MRM) mode. Source conditions were optimized as follows: spray voltage $+4000 \mathrm{~V}$; transfer capillary temperature $290^{\circ} \mathrm{C}$; argon was used as the collision gas at a pressure of $1.0 \mathrm{mTorr}(1$ torr $=133.322 \mathrm{~Pa})$. Determination was performed in the selected reactions monitoring mode using the two most intensive and specific fragment ions with a scan width of $0.06 \mathrm{~s}$. Optimized MS/MS parameters for the target antibiotics are shown in Table 1.

\subsection{Quality assurance and quality control}

Sample concentrations were calculated using the internal standard $\left({ }^{13} \mathrm{C}_{3}\right.$-caffeine) method, except for the chloramphenicols (chloramphenicol, thiamphenical, florfenicol) which were calculated using an external standard method. Calibration lines of seven concentration points (1.0, 2.0, 5.0, $10.0,20.0,50.0$ and $80.0 \mu \mathrm{g} / \mathrm{L}$ in methanol containing $0.1 \%$ formic acid, v/v), were used for quantification of individual antibiotics. The linearity of the calibration curve in this range was confirmed with a high linear correlation coefficient $\left(R^{2}>0.99\right)$. For manures and feeds, validations of the analytical method (e.g., the limits of quantification and 
recovery) were difficult to determine because the samples already contained some of the selected analytes (e.g., tetracycline, oxytetracycline, chlortetracycline, and sulfadiazine) and matrix interference was pronounced. Moreover, these validations are often done by spiking a standard solution before extraction, without any aging procedure, being a mean of validating the quantification of a spiked solution in an aqueous sample. In addition, ultrasonic extraction with methanol/EDTA-McIlvaine buffer has been successfully used for antibiotic analysis of manure by numerous workers [12,24-26]. We therefore, evaluated the quantification method (detection limits and recovery) of SAX-HLB SPE (clean-up and post-extraction), by spiking with a concentration $(50 \mathrm{ng} / \mathrm{L})$ in lake and tap water prior to SPE. The recovery rates $(69.7 \%-92.5 \%)$ were applied to clean-up this SPE extraction in our analysis of antibiotics (Table S1).

\section{Results and discussion}

\subsection{Occurrence of veterinary antibiotics in collected manures}

The occurrence of selected antibiotics in manures is presented in Figure 1(a). Tetracyclines (TC, OTC, CTC and DXC) and SD were the main contaminants in these solid samples, with maximum concentrations of individual contaminants reaching $98.2 \times 10^{3}, 354.0 \times 10^{3}, 139.4 \times 10^{3}$, $37.2 \times 10^{3}$, and $7.1 \times 10^{3} \mu \mathrm{g} / \mathrm{kg}$, respectively. The tetracyclines detected in these farms were in a similar order of magnitude to data previously collected from other swine farms in China (Figure 1(b)). This implies frequent use of these medicines in swine breeding. However, the occurrence profiles of these compounds in manures differed from the published data. It was likely that this was due to differing individual antibiotic prescription patterns in the local area studied. Greater attention must be given to bacterial resistance to tetracyclines, because tetracycline resistance genes have been found to be widespread in environmental matrices (there are more than 38 tetracycline resistance genes) [30,31]. In addition, tetracyclines are present in extremely high concentrations $(\mu \mathrm{g} / \mathrm{L})$ in wastewater from Chinese swine feedlots [32-34]; probably suggesting the ubiquitous application of these antibiotic in pig breeding. There is worldwide occurrence of tetracyclines (especially OTC and CTC) in lagoon samples or manures from livestock husbandry [25,26,35-37]; perhaps suggesting that these chemicals can be used as semi-quantitative markers in environmental research, as higher levels indicate higher inputs of livestock wastes.

Sulfonamides (including SD, SMX and SMT) occurred at lower detectable levels in manures (Figure 1(a)). This concurs with the findings of Zhao et al. [8], in which these compounds in pig dung collected from 8 provinces of China were below $0.84 \mathrm{mg} / \mathrm{kg}$. However, the levels of SMT and SMX that we found were much lower than in manures studied in the city of Tianjing, in North China, where concentrations ranged from 3.3-24.8 mg/kg for SMT and $0.23-5.7 \mathrm{mg} / \mathrm{kg}$ for SMX $[7,12]$. That these compounds were detected less frequently than tetracyclines may be due to the weak adsorption of sulfonamides and their tendency to persist in aqueous samples; high levels have been detected in swine wastewater [32,33]. NFC was also present at lower concentrations than reported by Zhao et al. [8] $(0.56-5.50 \mathrm{mg} / \mathrm{kg})$, but OFC was higher than found by $\mathrm{Hu}$ et al. [7] (approximately $15.7 \mu \mathrm{g} / \mathrm{kg}$ ). These differences were possibly due to differing prescription patterns in different areas, because variation in the occurrence of these medicines in swine wastewater has also been found [4,33,34]. NFC and OFC can reach levels that are tens of $\mu \mathrm{g} / \mathrm{L}$ in swine wastewater in central China (Hubei Province) and in Iowa and Ohio in the USA [4,33]. Macrolides (ETM$\mathrm{H}_{2} \mathrm{O}$ and RTM) and chloramphenicols (CPC, TPC and FFC) have been less frequently investigated in swine manure and we found them present at low concentrations. However, the detection of CPC in swine manures was likely the result of illegal use of this prohibited medicine; it has similarly been detected in chicken manure in Tianjing, North China [12]. Greater attention must be given to environmental contamination by this compound because of its relationship with plastic anemia in human. In fact, existing levels of CPC in river water or groundwater are relatively high at some Chinese
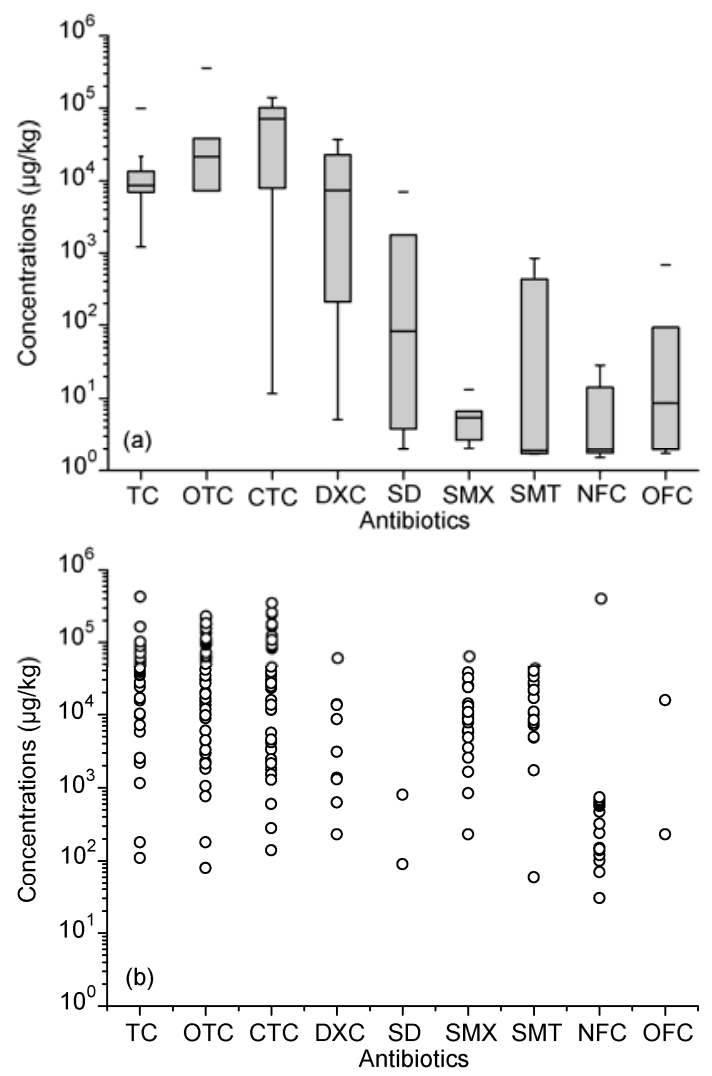

Figure 1 Occurrence of veterinary antibiotics in swine manures in China: from our results (a) and the literature (b) [7,8,12,27-29]. 
sampling sites [7,38], implying a serious environmental risk from this antibiotic at these locations.

\subsection{Variation in antibiotic levels among manures from different farms and animal types}

Animal operations may vary widely in the administration of medicine due to their different breeding performances, and the prescription pattern for different animal types and breeding seasons might also differ on the same farm. As a result, the occurrence of antibiotics in manures from a range of farms, animal types, or sampling seasons, understandably varies. Figure 2 shows the variation we found in levels of antibiotics present in manures. Among the main contaminants, CTC was the dominant residue in intensive operations, in contrast with OTC in individual household breeding (Figure 2(a)). This may have been due to the lower budget of the household breeding operation, because OTC is cheaper than CTC (http://www.syyl.org/index.asp). However, comparing the contaminating antibiotics in manures from these farms is complicated. Larger scale breeding feedlots did not show higher contamination levels of the veterinary drugs in the manures. Indeed, the smaller units showed the highest levels of some compounds (Figure 2(a)). Drug administration strategies and operational experience may explain the variation in occurrence of antibiotics in manures among the farms. Breeding seasons also affected the prescriptions given to animals, judging from the wide variation in analytes in the manures collected from the same farm during different seasons (Figure 2(b)). More tetracyclines and SD were applied to finishing pigs in winter to prevent and control gastrointestinal disorders and respiratory problems. In contrast, SMT and OFC are more frequently used in summer (Figure 2(b)), and these applications were indicated by the levels in animal excretion [2]. Moreover, the mode of administration of medicines also differed among animal types during breeding, resulting in variation in the compounds present in manure from different swine types (Figure 2(c) and (d)). Higher doses of antibiotics (especially those most frequently applied) appear to have
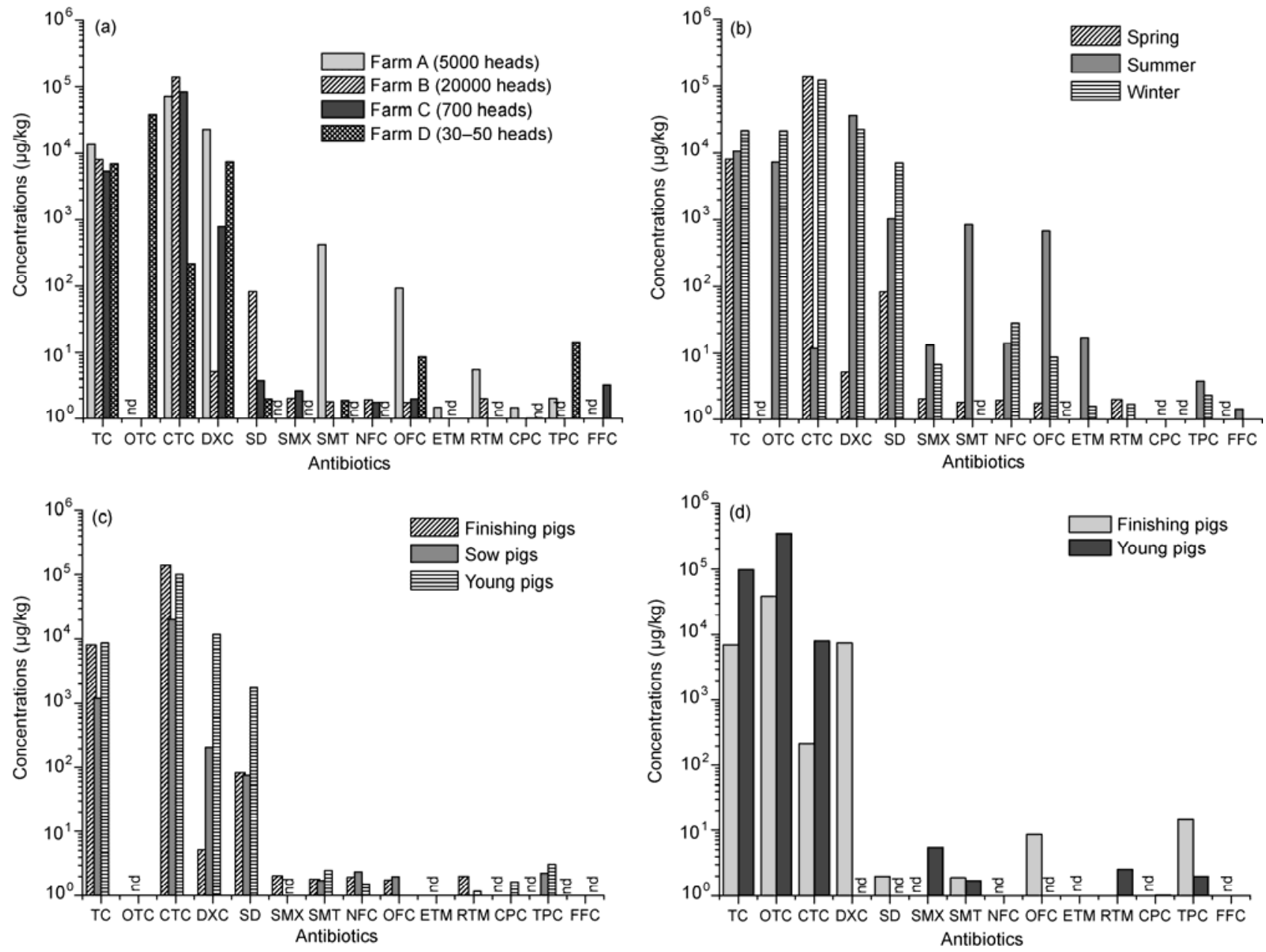

Figure 2 Variations in antibiotics levels among the manures from different farms, breeding seasons, and animal types. (a) Manure for finishing pig from different farms in spring season; (b) manure for finishing pig from Farm B in different seasons; (c) manure for different animal types from Farm B in spring season; (d) manure for different animal types from Farm D in spring season. "nd" means below the MDL. 
been given to young pigs (Figure 2 (c) and (d)). However, the excretion rate or metabolizable capacity by different organi- sms can also affect the occurrence of antibiotics in manures [39].

\subsection{Residues of the selected antibiotics in manure management}

Manure management decisions made to hasten the degradation of antibiotics are very important in preventing medicines and metabolites from being directly or indirectly released into the environment [40]. Two manure administration methods (storage and vermiculture) were used on the studied farms for management of large quantities of manure. Unfortunately, these systems showed limited capability to reduce pollution levels of the main contaminants (TC, OTC, CTC, DXC and SD; other compounds were not considered here because of their lower detection rates). We found high levels of these chemicals remaining in the manure (Figure 3 ). Storage time had little effect on degradation of antibiotics (compared with average values), except for OTC, perhaps because of variable detection of OTC in manure (the manure source utilized for storage may contain lower OTC, Figure 2). Similarly, Boxall [18] reported that tetracyclines
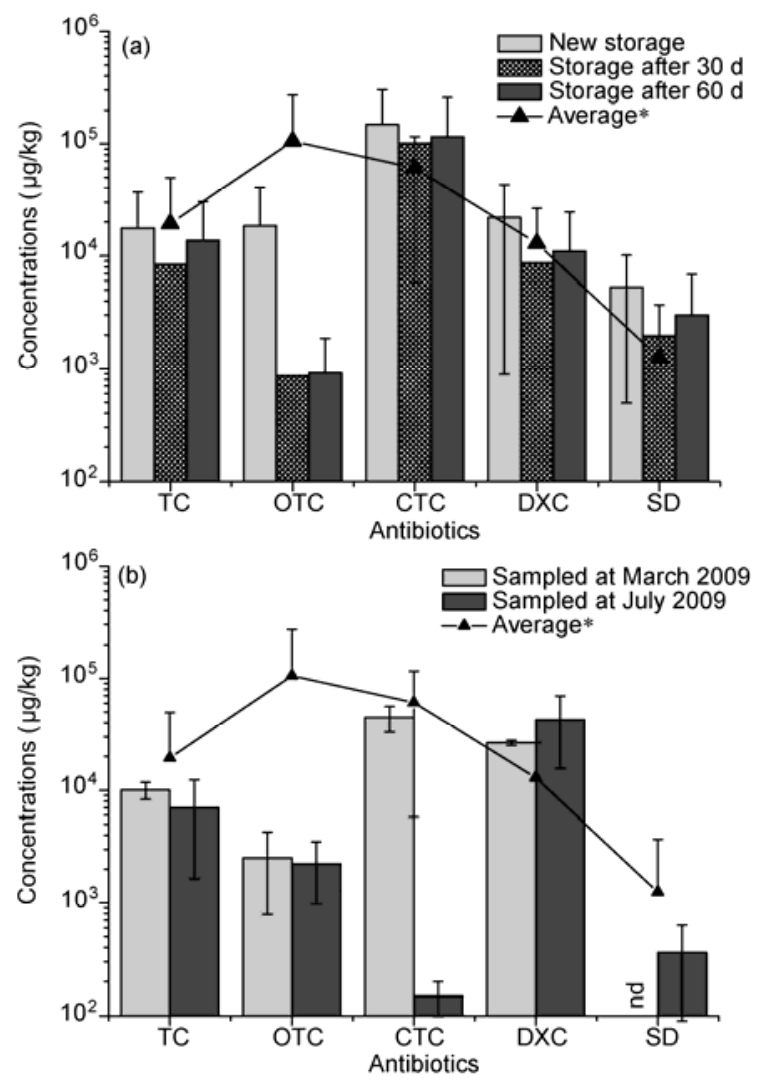

Figure 3 Residues of selected antibiotics in manures during manure storage (a) and vermiculture (b). Some comparisons are unavailable such as those manures collected at differing times or during different seasons, due to differing manure sources from each other; * refers to the average values of the manures we analyzed; "nd" means below the MDL. have long half-lives of many months and are therefore likely to persist during manure storage. However, SD showed minimal metabolism during storage in contrast with its lower persistence during manure storage with a half-life of $<30 \mathrm{~d}$ [18]. This may have been due to the properties of the manure (e.g., water content or redox status) or the dynamics of conversion between conjugates and parent compounds $[18,41]$.

Vermiculture was expected to effectively deplete antibiotics through biological activity. However, high concentrations of the compounds also remained in the vermicompost (Figure 3(b)). The greater degradation of CTC in the July 2009 sampling season may have been attributable to the lower doses of this medicine used in the summer breeding season (Figure 2) Another possible explanation for the effective dissipation of SD during vermiculture is that SD might migrate to other water bodies because of its weak adsorption [42]. Moreover, dilution can also affect the concentrations of veterinary antibiotics in vermicomposts, as other organic materials (e.g., straw) are usually added to the manure to promote vermicomposting.

Tetracyclines were also frequently detected in agricultural soils, implying their transfer from manure to soil (Table S2). CTC was the predominant contaminant despite the structural similarities of these compounds. This may have been due to their occurrence and stability in manure and soil [43]. CTC measured in the pear orchard and paddy field soils was higher than the soil trigger value $(100 \mu \mathrm{g} / \mathrm{kg})$ set by the Steering Committee of the Veterinary International Committee on Harmonization (VICH). This level was based on the ecotoxic effects of antibiotic compounds on a range of organisms. The low detection of sulfonamides (SD, SMX and SMT) in the agricultural soils we sampled is assumed to result from the mobility of these compounds in soil-water systems [40]. Relatively high detection of quinolones (NFC and OFC), comparing with their detection frequencies in manure, might be due to the adsorbability and stability of this class of antibiotic [44]. Concentrations of other antibiotics found in soil paralleled their detection levels in manure samples. In addition, differences in the concentrations we detected in the agricultural soils (Table S2) appeared to be due to differences in application rates of manure.

\subsection{Evaluation of contribution of veterinary antibiotics from feeds}

Most antibiotics utilized in animal husbandry are administered in feed, including prescription medicines and growth promoters [2]. The feeds we obtained from the selected farms were found to contain some of the target antibiotics investigated, with a range of average concentrations between 0.2 and $46.8 \mu \mathrm{g} / \mathrm{kg}$ (Table S3). The occurrence of the antibiotics in feces was likely to be a reflection of the animal feeds used, because of their high rate of excretion (up to $75 \%$ of the parent compound or metabolite) in the feces [2]. 
However, the predicted concentrations calculated on the basis of detection in animal feeds were much lower than the actual concentrations of veterinary antibiotics we found in the manure (Figure 4), indicating that another administration route may have been involved on these farms, such as injection or special oral treatment. This contrasts with the situation in developed countries, in which $80 \%-95.1 \%$ of veterinary antibiotics given to animals are administered as feed additives [2]. Antibiotic administration via medicated feeding stuffs and drinking water seems more practical because this mode of application allows the treatment of whole animal herds over extended periods of time [45]. In China, however, conventional practices may be different in animal feedlots, especially in small facilities because of poor management (Figure 2, a reflection of drug application). Addition to feed was also conducted to prevent diseases such as gastrointestinal disorders and respiratory problems. However, a large proportion of drugs are applied to animals by injection or by other modes of oral application against epidemic diseases depending on breeding stage and season. Thus, the extremely high concentrations of antibiotics found in these manures were unlikely to be from daily feed applications but were from other administration modes; for the prevention of epidemic diseases. Greater attention needs to be given to the overall pattern medicine use on Chinese farms because a proportion of the antibiotics used will be removed in urine [2]. In China, this is always discharged to wastewater and separated from the manure. In fact, high levels of polluting antibiotics have often been found in swine wastewater [32-34]. Lower contamination levels of other compounds may be attributable to feed application only because of the similarities between actual concentrations and predicted values (Figure 4). In addition, lower concentrations of these compounds (compared with tetracyclines and SD) were also found in wastewaters from these farms [34].

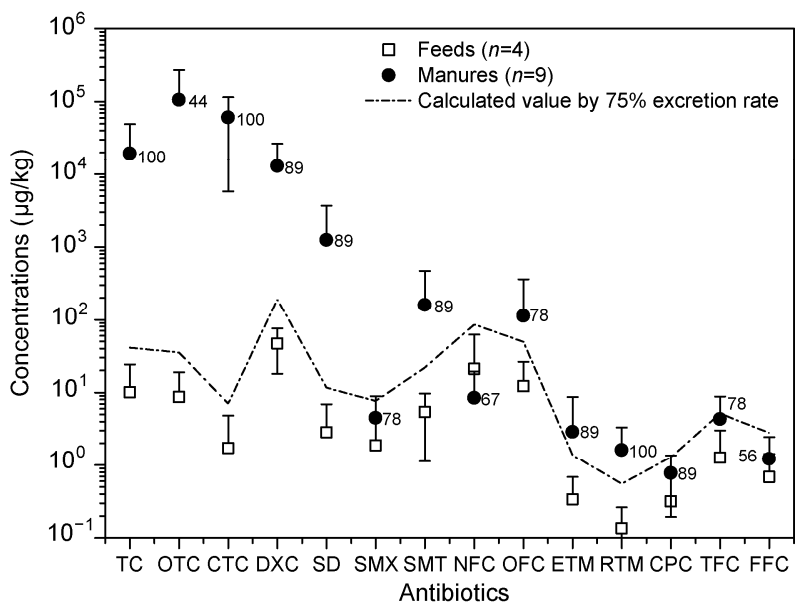

Figure 4 Comparison of actual concentrations and predicted concentrations of antibiotics (the number near the dark spot is the detection frequency).
Calculation was on the basis of the following formula

$$
\mathrm{CV}=\frac{C_{f} \times D \times \mathrm{ER}}{E M \times \mathrm{DM} \%},
$$

where $\mathrm{CV}$ is the calculated value in $\mu \mathrm{g} / \mathrm{kg} ; C_{f}$ is the average concentrations of antibiotics in swine feeds in $\mu \mathrm{g} / \mathrm{kg} ; D$ is the daily intake of feeds for swine in $\mathrm{kg} / \mathrm{d}$; referring to the "Breeding standard of swine" from the Ministry of Agriculture of the People's Republic of China (NY/T65-2004) [46], $D$ was taken as $2.5 \mathrm{~kg} / \mathrm{d}$ in this calculation; ER is the excretion rate of the antibiotics consumed by swine, taking the maximum value (75\%) for calculation following Sarmah et al. [2]; $E M$ is the manure discharge quantity from each pig in $\mathrm{kg} / \mathrm{d}$, according to the Department of Nature and Ecology Conservation, Ministry of Environmental Protection of the People's Republic of China [47]; $2.0 \mathrm{~kg} / \mathrm{d}$ (wet weight) per pig can be produced in intensive breeding; DM\% is the dry matter content of the manure, 23\% was used in the calculation following average in our samples.

\section{Conclusions}

Fourteen antibiotics from five classes were detected at four swine farms at two sampling surveys in East China. The contaminants present in high concentrations were TC, OTC, CTC, DXC and SD, with maximum concentrations of the individual contaminants reaching $98.2 \times 10^{3}, 354.0 \times 10^{3}$, $139.4 \times 10^{3}, 37.2 \times 10^{3}$, and $7.1 \times 10^{3} \mu \mathrm{g} / \mathrm{kg}$, respectively. The ranges of these compounds in manure samples were in the same order of magnitude as have been previously reported in China. However, the actual occurrence of these compounds was dependent on breeding scale, animal type, and breeding season. Management such as manure storage and vermiculture cannot effectively reduce the pollution levels of the main contaminants effectively, resulting in high levels of these chemicals remaining in manure. The occurrence of these antibiotics in agricultural soils collected from four types of agricultural land near the farms was thus a reflection of manure application. Our comparison of the concentrations of veterinary antibiotics in manure and predicted concentrations calculated on the basis of detection in the animal feeds used, suggests that the contribution from feed consumption was small. High antibiotic contamination in solid samples was therefore resultant from antibiotics administered by other methods.

We thank Dr Guanjiu Hu and Dr Yonggang Zhao of the Environmental Monitoring Center, Jiangsu Province, for their kind help in antibiotic analysis using UPLC-MS/MS. We also thank Peter Christie, from the Department of Agriculture and Rural Development for Northern Ireland, Agri-Environment Branch, Agri-Food and Biosciences Institute, for his kind help with language polishing. This work was supported by Water Special Project (2008ZX07101-006-05) and knowledge Innovation program of the Chinese Academy of Sciences (KZCX2-YW-Q02-02-04). 
1 Boxall A B A, Kolpin D W, Halling-Sørensen B, et al. Are veterinary medicines causing environmental risk? Environ Sci Technol, 2003, 37: 287A-294A

2 Sarmah A K, Meyer M T, Boxall A B A. A global perspective on the use, sales, exposure pathways, occurrence, fate and effects of veterinary antibiotics (VAs) in the environment. Chemosphere, 2006, 65: 725-759

3 Bound J P, Voulvoulis N. Pharmaceuticals in the aquatic environment - A comparison of risk assessment strategies. Chemosphere, 2004, 56: 1143-1155

4 Campagnolo E R, Johnson K R, Karpati A, et al. Antimicrobial residues in animal waste and water resources proximal to large-scale swine and poultry feeding operations. Sci Total Environ, 2002, 299: 89-95

5 Batt A L, Snow D D, Aga D S. Occurrence of sulfonamide antimicrobials in private water wells in Washington County, Idaho, USA. Chemosphere, 2006, 64: 1963-1971

6 Matsui Y, Ozub T, Inouec T, et al. Occurrence of a veterinary antibiotic in streams in a small catchment area with livestock farms. Desalination, 2008, 226: 215-221

7 Hu X G, Zhou Q X, Luo Y. Occurrence and source analysis of typical veterinary antibiotics in manure, soil, vegetables and groundwater from organic vegetable bases, northern China. Environ Pollut, 2010, 158: 2992-2998

8 Zhao L, Dong Y H, Wang H. Residues of veterinary antibiotics in manures from feedlot livestock in eight provinces of China. Sci Total Environ, 2010, 408: 1069-1075

9 Kemper N. Veterinary antibiotics in the aquatic and terrestrial environment: A review. Ecol Indic, 2008, 8: 1-13

10 Morley N J. Environmental risk and toxicology of human and veterinary waste pharmaceutical exposure to wild aquatic host-parasite relationships. Environ Toxicol Pharmacol, 2009, 27: 161-175

11 Ben W W, Qiang Z M, Pan X, et al. Removal of veterinary antibiotics from sequencing batch reactor (SBR) pretreated swine wastewater by Fenton's reagent. Water Res, 2009, 43: 4392-4402

12 Hu X G, Yi L, Zhou Q X, et al. Determination of thirteen antibiotics residues in manure by solid phase extraction and high performance liquid Chromatography. Chinese J Anal Chem, 2008, 36: 1162-1166

13 Xian Q M, Hu L X, Chen H C, et al. Removal of nutrients and veterinary antibiotics from swine wastewater by a constructed macrophyte floating bed system. J Environ Manage, 2010, 91: 2657-2661

14 Zhang H M, Zhang M K, Gu G P. Residues of tetracyclines in livestock and poultry manures and agricultural soils from north Zhejiang Province (in Chinese). J Eco Rural Environ, 2008, 24: 69-73

15 Chang X S, Meyer M T, Liu X Y, et al. Determination of antibiotics in sewage from hospitals, nursery and slaughter house, wastewater treatment plant and source water in Chongqing region of Three Gorge Reservoir in China. Environ Pollut, 2010, 158: 1444-1450

16 Bernal M P, Alburquerque J A, Moral R. Composting of animal manures and chemical criteria for compost maturity assessment: A review. Bioresour Technol, 2009, 100: 5444-5453

17 Dolliver H, Gupta S, Noll S. Antibiotic degradation during manure composting. J Environ Qual, 2008, 37: 1245-1253

18 Boxall A B A. Fate of veterinary medicines applied to soils. In: Kümmerer K, ed. Pharmaceuticals in the Environment. Berlin Heidelberg: Springer, 2008. 103-119

19 National Bureau of Statistics of China. China Statistical Yearbook 2009. http://www.stats.gov.cn/tjsj/ndsj/

20 Jin X C, Xu Q J, Huang C Z. Current status and future tendency of lake eutrophication in China. Sci China Ser C-Life Sci, 2005, 48: 948-954

21 Guo L. Doing battle with the green monster of Taihu Lake. Science, 2007, 317: 1166

22 Mcardell C S, Molnar E, Suter M J, et al. Occurrence and fate of macrolide antibiotics in wastewater treatment plants and in the Glatt Valley watershed, Switzerland. Environ Sci Technol, 2003, 37: 5479-5486

23 Li Y W, Mo C H, Zhao N, et al. Determination of sulfonamides anti- biotics in water and soil using high performance liquid chromatography (in Chinese). Chinese J Anal Chem, 2008, 36: 954-958

24 Blackwell P A, Holten Lützhøft H C, Ma H P, et al. Ultrasonic extraction of veterinary antibiotics from soils and pig slurry with SPE clean-up and LC-UV and fluorescence detection. Talanta, 2004, 64: 1058-1064

25 Martínez-Carballo E, González-Barreiro C, Scharf S, et al. Environmental monitoring study of selected veterinary antibiotics in animal manure and soils in Austria. Environ Pollut, 2007, 148: 570-579

26 Karcı A, Balcıŏlu I A. Investigation of the tetracycline, sulfonamide, and fluoroquinolone antimicrobial compounds in animal manure and agricultural soils in Turkey. Sci Total Environ, 2009, 407: 46524664

27 Guo B. The study on occurrence and the environmental risk of antibiotics in animal waste applied to land (in Chinese). Master Dissertation. Guangzhou: Jinan University, 2009. 29

28 Zhang S Q. Analysis of harmful and components and harmless processing of livestock and poultry manures (in Chinese). Dissertation for Postdoctoral. Beijing: Graduate School of Chinese Academy of Agricultural Sciences, 2004. 11

29 Zhang H M, Zhang M K, Gu G P. Residues of tetracyclines in livestock and poultry manures and agricultural soils from north Zhejiang Province (in Chinese). J Ecol Rural Environ, 2008, 24: 69-73

30 Kobayashi T, Suehiro F, Tuyen B C, et al. Distribution and diversity of tetracycline resistance genes encoding ribosomal protection proteins in Mekong river sediments in Vietnam. FEMS Microbiol Ecol, 2007, 59: 729-737

31 Zhang X X, Zhang T, Fang H H. Antibiotic resistance genes in water environment. Appl Microbiol Biotechnol, 2009, 82: 397-414

32 Ben W W, Qiang Z M, Adams C, et al. Simultaneous determination of sulfonamides, tetracyclines and tiamulin in swine wastewater by solid-phase extraction and liquid chromatography-mass spectrometry. J Chromatogr A, 2008, 1202: 173-180

33 Tong L, Li P, Wang Y X, et al. Analysis of veterinary antibiotics residues in swine wastewater and environmental water samples using optimized SPE-LC/Ms/Ms. Chemosphere, 2009, 74: 1090-1097

34 Chen Y S, Zhang H B, Luo Y M, et al. A preliminary study on the occurrence and dissipation of antibiotics in swine wastewater (in Chinese). Acta Sci Circumstantiae, 2010, 30: 2205-2212

35 Christiana T, Schneidera R J, Färberb H A, et al. Determination of antibiotic residues in manure, soil and surface waters. Acta Hydrochim Hydrobiol, 2003, 31: 36-44

36 Jacobsen A M, Halling-Sørensen B. Multi-component analysis of tetracyclines, sulfonamides and tylosin in swine manure by liquid chromatography-tandem mass spectrometry. Anal Bioanal Chem, 2006, 384: 1164-1174

37 Aust M O, Godlinski F, Travis G R, et al. Distribution of sulfamethazine, chlortetracycline and tylosin in manure and soil of Canadian feedlots after subtherapeutic use in cattle. Environ Pollut, 2008, 156: 1243-1251

38 Xu W H, Zhang G, Zou S C, et al. Determination of selected antibiotics in the Victoria Harbour and the Pearl River, South China using high-performance liquid chromatography-electrospray ioization tandem mass spectrometry. Environ Pollut, 2007, 145: 672-679

39 Winckler C, Grafe A. Use of veterinary drugs in intensive animal production: Evidence for persistence of tetracycline in pig slurry. $\mathbf{J}$ Soil Sediment, 2001, 1: 66-70

40 Arikan O A, Mulbry W, Rice C. Management of antibiotic residues from agricultural sources: Use of composting to reduce chlortetracycline residues in beef manure from treated animals. J Hazard Mater, 2006, 164: 483-489

41 Sukul P, Spiteller M. Sulfonamides in the environment as veterinary drugs. Rev Environ Contam Toxicol, 2006, 187: 67-101

42 Burkhardt M, Stamm C, Waul C, et al. Surface runoff and transport of sulfonamide antibiotics and tracers on manured grassland. J Environ Qual, 2005, 34: 1363-1371

43 Zilles J, Shimada T, Jindal A, et al. Presence of macrolide-lincosamide-streptogramin B and tetracycline antimicrobials in swine waste treatment processes and amended soil. Water Environ Res, 2005, 77: 
$57-62$

44 Thiele-Bruhn S. Pharmacetical antibiotic compounds in soils-A review. J Plant Nutr Soil Sci, 2003, 166: 145-167

45 Ungemach F R, Muller-Bahrdt D, Abraham G. Guidelines for prudent use of antimicrobials and their implications on antibiotic usage in veterinary medicine. Int J Med Microbiol, 2006, 296(Suppl 2): $33-38$
46 Department of Nature and Ecology Conservation, Ministry of Environmental Protection of the People's Republic of China. Pollution Investigation and Control Countermeasure for National Livestock and Poultry Breeding (in Chinese). Beijing: China Environmental Science Press, 2008. 14-103

47 Ministry of Agriculture of the People's Republic of China. Breeding Standard of Swine, NY/T65-2004 (in Chinese)

Open Access This article is distributed under the terms of the Creative Commons Attribution License which permits any use, distribution, and reproduction in any medium, provided the original author(s) and source are credited.

\section{Supporting Information}

Table S1 Recovery and method detection limits (MDL ${ }^{\mathrm{a})}$ ) in water

Table S2 Occurrence of veterinary antibiotics in soil collected from four agricultural fields near the studied farms ( $\mu \mathrm{g} / \mathrm{kg})$

Table S3 Occurrences of veterinary antibiotics in feeds collected from the studied farms $(\mu \mathrm{g} / \mathrm{kg})$

The supporting information is available online at csb.scichina.com and www.springerlink.com. The supporting materials are published as submitted, without typesetting or editing. The responsibility for scientific accuracy and content remains entirely with the authors. 